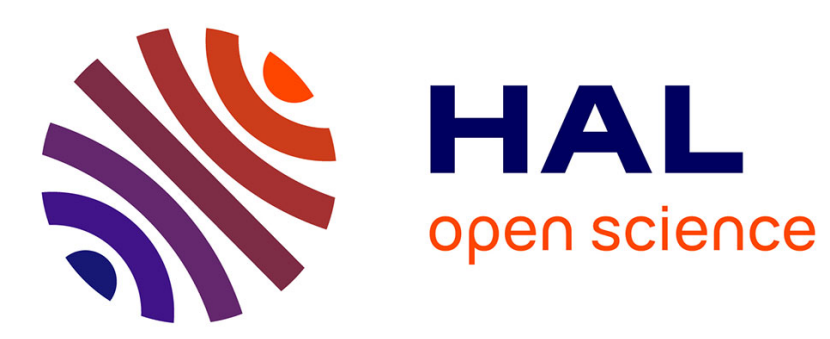

\title{
La Horticultura Yanomami y la Problemática de los Medios de Sabanas en la Amazonía Venezolana
}

\author{
Catherine Alès
}

\section{To cite this version:}

Catherine Alès. La Horticultura Yanomami y la Problemática de los Medios de Sabanas en la Amazonía Venezolana. C. Alès \& J. Chiappino (dir.). Caminos Cruzados. Ensayos en Antropología Social, Etnoecología y Etno-educación, IRD Editions/ULA-GRIAL, pp.389-422, 2003. halshs-02546368

\section{HAL Id: halshs-02546368 \\ https://shs.hal.science/halshs-02546368}

Submitted on 21 Apr 2020

HAL is a multi-disciplinary open access archive for the deposit and dissemination of scientific research documents, whether they are published or not. The documents may come from teaching and research institutions in France or abroad, or from public or private research centers.
L'archive ouverte pluridisciplinaire HAL, est destinée au dépôt et à la diffusion de documents scientifiques de niveau recherche, publiés ou non, émanant des établissements d'enseignement et de recherche français ou étrangers, des laboratoires publics ou privés. 
2003 « La Horticultura Yanomami y la Problemática de los Medios de

Sabanas en la Amazonía Venezolana », in C. Alès \& J. Chiappino (dir.), Caminos Cruzados. Ensayos en Antropología Social, Etnoecología y Etnoeducación, Mérida, IRD Editions/ULA-GRIAL : 389-422.

\section{La horticultura yanomami y la problemática de los medios de sabanas en la Amazonía venezolana}

Catherine Alès*

La presencia de zonas de sabanas en el marco del ecosistema de la Amazonía venezolana, planteó un problema en cuanto a su formación. Se ha dado énfasis a varios factores tanto de orden edáfico como climático o antropogénico. En este texto examinaremos más particularmente el caso de las sabanas de la Sierra Parima, así como las distintas hipótesis propuestas en relación con su origen. A la luz de este ejemplo, el tema de la utilización del factor antropogénico dentro del marco de los estudios del medio ambiente será aquí discutido desde el punto de vista metodológico. La formación de las sabanas en las tierras altas de la Sierra Parima nos llevará a reflexionar sobre el modo de explotación del medio por las poblaciones autóctonas; en efecto, este territorio se encuentra actualmente ocupado por comunidades esencialmente yanomami y sanïma. No obstante veremos que es igualmente importante tomar en cuenta el factor histórico.

El tópico de las sabanas de la Sierra Parima fue primeramente considerado por W. Smole, geógrafo norteamericano, quien publica en 1976 un libro sobre los tierras altas de ésta. En su texto, Smole sostiene que las sabanas de la Sierra Parima son el resultado del modo de explota-

${ }^{*}$ Centre National de la recherche Scientifique (CNRS), Paris. 
ción del medio por los Yanomami durante siglos. El mismo título de la obra "The Yanoama Indians: a Cultural Geography", subraya este particular. Según Smole, las sabanas se han formado en el curso de los siglos debido a la explotación del bosque por los Yanomami dentro del marco de su práctica de la horticultura de quema forestal. El autor apoya su hipótesis en los datos demográficos que obtuvo a su paso por ese territorio $^{1}$. En su libro ofrece cálculos de superficies de conucos que proyecta sobre siglos, calcúlos que basa sobre superficies de la época (1971) -y sobre una cifra de población que es también de la misma época. Para apoyar su tesis menciona un solo caso de conuco, no hay detalles en cuanto a su nombre o ubicación, que se habría transformado en sabana.

En un artículo colectivo dirigido por Otto Huber, botánico especialista de las sabanas en Venezuela (O. Huber, J. A. Steyermarck, G. T. Prance \& C. Alès 1984a), señala la inadecuación de las bases de los cálculos de Smole, así como el problema de índole histórico de hacer de los Yanomami los únicos habitantes de esta área durante siglos (ver Alès 1984a). En ese texto, que presenta una recensión del estado de los conocimientos sobre el tema, los autores exhortan a la prudencia en este tipo de estudios, concluyendo que no podían realizarse sin tomar en cuenta diversos tipos de factores, especialmente edáficos y climáticos e igualmente históricos y sociológicos. Más recientemente, Smole ha publicado de nuevo un artículo sobre aquel tema en la obra colectiva dirigida por Darrel Posey y William Baylée en 1989. Aquí reproduce casi en los mismos términos la tesis emitida en su libro de 1976 sin aportar nuevos argumentos referentes a los contenidos en su obra anterior.

Su tesis consiste en considerar la horticultura practicada por los Yanomami como la causa de las alteraciones del medio ambiente. No obstante, fundamentalmente, los Yanomami comparten la misma técnica de horticultura usada por todos los pueblos que viven en esta región, si la única causa fuese la horticultura y el modo de explotación practicado por los Yanomami, entonces la selva amazónica en todas aquellas partes que fueron y están actualmente habitadas por Amerindios debería presentar daños similares. Debemos contemplar, en consecuencia, otras explicaciones más complejas. Tal como yo concluía en mi artículo, los Yanomami 
de mayor edad recuerdan haber siempre visto las sabanas de gramíneas, tal como existen actualmente, en la Parima A y B. Ya existían cuando el grupo que formó las veinticinco comunidades que viven actualmente alrededor de la Parima B se instaló por primera vez en esos lugares.

\section{Descripción del medio}

Los Yanomami de la Sierra Parima distinguen esencialmente cuatro grandes tipos de paisajes vegetales:

- urufi o el bosque;

- perïsï o las sabanas de gramíneas, cuya planta dominante lleva el nombre de perïsi;

- mõromôroma o las sabanas de helechales, cuya especie dominante (Pteridium aquilinum, var. arachnoidum) lleva el nombre de mõromõroma; - a los cuales se añaden los conucos (fikari kano), nuevos (tute thë ka) y antiguos (suwëpata).

Existen pues dos tipos de sabanas, las de gramíneas y las de helechales. Las primeras se encuentran concentradas en los sectores de Parima A, Parima B y en la orilla derecha del alto Ocamo y de las cabeceras del Ocamo. Están bien localizadas y registradas por los autóctonos. El segundo tipo de sabana es el más extenso, se trata de sabanas de helechales que se encuentran de manera privilegiada en los altos de las colinas y de los acantilados. Existen vastos sectores de helechales a lo largo de la división de las aguas del Orinoco-Amazonas de la Sierra Parima y, en general, en las cimas de los cerros cerca de las regiones de sabanas de gramíneas ${ }^{2}$. Sin embargo, contrariamente a la región de los llanos, son las sabanas las que aparecen como islas mientras que prevalece el paisaje de bosque.

Tradicionalmente los Yanomami no vivían en las sabanas pero sí en el bosque, ya sea en campamentos elementales o en habitaciones colectivas más elaboradas. Cuando se instalan en región de sabana no se implantan en su centro sino siempre en la orilla de la misma en el bosque. Esta opción es motivada por razones culturales, el deseo de protección, primero con relación a un enemigo eventual (los Yanomami prefieren vivir escondidos en los bosques), y segundo por el miedo a las neblinas 
(mahari) que aparecen en las sabanas de gramíneas. Las sabanas llevan igualmente la marca del gran demonio de las enfermedades, como lo prueba la presencia de "cárcavas" (grietas de erosión) en algunas de ellas. Cuando se instalaron en la orilla de sabana, los Yanomami de la Parima A y B, imperaban razones coyunturales: fue cuando el bosque se quemó y el humo se quedó durante meses. Luego de este período, en el que el miedo de quemarse los obligó a dejar su vivienda, shapono, en el corazón del bosque, los Yanomami regresaron a este último. Los misioneros evangelistas les harían venir más tarde a las sabanas, explicándoles que el bosque es peligroso.

Sabemos desde luego que no habitaban las sabanas y que la ocupación habitacional de éstas es muy reciente. La cultura yanomami es por excelencia una cultura de bosque y no de sabana. Además de que esos dos tipos de sabanas no son indicados para el modo de agricultura practicado por los Yanomami, no presentan ningún interés como territorio de caza potencial. Solo una zona de bosque tipo galería en la ribera de los ríos, y algunas colonias de moriches en las depresiones pantanosas en la sabana de Parima B, son explotadas como bosque. Ese patrón económico domina todavía; únicamente ha cambiado el modelo de vivienda, con la instalación de casas colectivas en el centro de las sabanas de gramíneas. Este esquema se ha difundido a partir de la instalación de los napë pë nü, los extranjeros, es decir, de los misioneros evangelistas de las Nuevas Tribus, después de 1968. Los Yanomami, imitando a los extranjeros, ya no temen entonces instalarse al descubierto. Por otra parte, en 1980, los misioneros han intentado implantar ganado y cochinos domésticos en las sabanas de gramíneas, pero aquellas dos experiencias resultaron negativas y abortaron rápidamente (C. Alès \& J. Chiappino 1994). En resumidas cuentas, hoy por hoy, la utilización de estas sabanas es exclusivamente de orden residencial y logístico (pista de aterrizaje para los aviones y avionetas), es una utilización reciente y exógena.

\section{Histórico}

¿Qué es lo que se puede describir del historial de los grupos que pueblan actualmente esta región? Se puede confirmar que todos los 
Yanomami que viven actualmente en la región vienen de otra parte. Sus antepasados llegaron desde el este, de Brasil. Prácticamente todas las comunidades que viven hoy en día en el norte del Orinoco y una parte de las que viven al sur, han seguido rutas migratorias que pasan por la Sierra Parima. La memoria de sus orígenes se concentra sobre una distancia aproximada comprendida entre la actual Parima A y el lado derecho de las cabeceras del Orinoco (cf. Alès 1984a).

Cuando los antepasados de los Yanomami que viven actualmente en las sabanas de Parima B llegan a esos lugares, hace más de sesenta años, descubren vestigios del paso de anteriores moradores. Encuentran matas cultivadas que se quedaron en el borde de la sabana (guayaba, piña) y sobre todo antiguas parcelas de conucos. El bosque ya se ha reconstituido, comprende especímenes de árboles imponentes (apia kë fii) pero a los cuales se mezclan todavía retoños de ciertas especies de bananos (rokomï $k \ddot{e}$ si, paishimi kësi), aguacates de gran tamaño, dando evidencia de la antigüedad del abandono del conuco ${ }^{3}$. Retoños de Guilielma gasipaes todavía se encontraban allí.

Los Yanomami que habitan actualmente los alrededores de la Parima B no son pues los primeros sino los últimos que han llegado. Lejos de observar una población sedentaria instalada desde siglos en esas sabanas, nos encontramos con grupos diferentes que se movieron en el transcurso de decenios y se han establecido de nuevo a medida de su progresión dentro del territorio hoy en día cubierto por dicho grupo cultural. Los Yanomami que viven al Norte y al Oeste, como los Sanïma, y los otros grupos de comunidades yanomami conocidos con el nombre de "Shiitari" o de "Kopari", pasaron en sus migraciones por y/o cerca de esta zona. No obstante esas son migraciones relativamente recientes, veremos en adelante que sociedades diferentes ocuparon el territorio antes de los Yanomami.

En realidad, cuando llegan a la región de lo que se llama ahora Parima B, no saben quiénes fueron los que pasaron antes de ellos y de los cuales sus abuelos descubren los rastros. Ellos reconstituyen actualmente el orden de las migraciones en el área, pero eso no quiere decir que todos se hayan instalado a orillas de las sabanas, puesto que algunos circularon por una ruta migratoria situada más al oeste de Parima B. Piensan que los 
primeros que transitaron por allá serían los ancestros de los actuales Sanïma que viven en el norte de su territorio. El grupo formado por los denominados "Hokomawë" viene luego; se trata de un grupo de comunidades intermediario desde el punto de vista lingüístico entre los Yanomamï y los Sanïma; vive actualmente entre las cabeceras del río Ocamo y las del río Matacuni. Vienen luego los pueblos “Kopari”, que se encuentran hoy día instalados entre las cabeceras del río Ocamo, y el río Matacuni. Luego pasan igualmente hacia el oeste los ancestros de las actuales comunidades "Shiitari", las cuales viven al interior de los dos lados del alto río Ocamo, a la altura y más arriba del raudal Arata.

Ellos mismos, hace más de sesenta años, cuando llegaron a esos lugares, representan un grupo proveniente del Oeste, el cual realizó una larga trayectoria circular desde el Este pasando por el Sur (al nivel de la región de la misión evangelista de Koyowë). Constituyen una sola casa colectiva oshapono. Son poco numerosos. Luego, se agregan a ellos varias familias que huyeron de la región de la Parima A. Crecieron y se separaron en tres viviendas y, en un período de cuarenta años, en cuatro pequeñas casas. Esta configuración dará paso al nacimiento de seis shapono antes de 1980, luego a veinticinco a partir de 1992.

\section{Agricultura y herramientas de metal}

Respecto al tema de la horticultura, ¿cuándo llegan a los Yanomami las primeras herramientas metálicas y cómo explotaron ellos el bosque antes de tenerlas?

Las primeras herramientas de acero se obtienen por intercambios realizados con las comunidades situadas al Este, sobre la pendiente brasileña. Esto se sitúa en el tiempo hace unos 50 años (aproximadamente antes de 1950). Los instrumentos metálicos pasan de comunidad a comunidad: en la región de la Parima A, la comunidad más cercana al Brasil es la primera en conseguirlas, luego las otras comunidades de Parima $A$ las adquieren a su vez de la misma manera; por fin, las aldeas de Parima $B$ las cambian con las de Parima A. Durante muchos años los Yanomami de aquella región no tendrán otras fuentes de abastecimiento sino cuatro 
fragmentos de hoja de machete usados, montados sobre un mango de madera (haoa) que les llegaron por intermedio de una comunidad (Hokomawëtheri) que vivía al Norte, en las fuentes del río Ocamo y en contacto con las comunidades sanïma ${ }^{4}$. De hecho, no tenían antaño muchas herramientas de metal. El que poseía una, se la prestaba a los otros de su comunidad. No se trataba de herramientas en buen estado, sino de lo que quedaba de ellas después de mucho uso: fragmentos de cuchillos o de machetes, muñones de hachas. Progresivamente el número de este tipo de instrumentos usados creció hasta llegar, en los años 60, a cuatro y hasta cinco por comunidad, pero nunca fue importante antes de la llegada de los misioneros.

El año 1961 marca la fecha en la cual, la FAB (Fuerza Aérea del Brasil) ignorando que se encontraban del lado venezolano, intentan instalarse en una sabana construyendo una pista de aterrizaje que llamaron Parima A, y lo repitieron luego en otra sabana ubicada más al noroeste que llamaron Parima B. Los brasileños y un misionero evangélico que les acompañaba entregan entonces a los Yanomami-durante los pocos meses de su estadía- una cantidad relativamente grande de herramientas metálicas: machetes, cuchillos, hachas... Son los primeros machetes y hachas nuevas que los Yanomami de aquella región veían. Luego los Yanomami se quedarán con esos instrumentos brasileños hasta la llegada -al final de 1968- de los misioneros de las New Tribes Missions a Parima $\mathrm{B}$, los cuales se convierten entonces en los nuevos proveedores de herramientas nuevas para toda el área. Mientras tanto no obtienen sino una sola herramienta de los Yanomami del Sur (denominados "Shamatari" por ellos) pues estaban en guerra con ellos. Estos últimos deben conseguirlas a través del intercambio con las comunidades en relación con las misiones del alto Orinoco. Por el contrario, después de la aparición de las herramientas brasileñas, todas las comunidades situadas en la zona interfluvial del alto Ocamo y las que viven en el Norte en las tierras altas se abastecen cerca de los Yanomami de Parima B; desde que están en paz, también intercambian los poblados cercanos al Sur de la Parima B. Esta cadena de intercambio perdura hasta nuestros días (Alès \& Chiappino $1994)^{5}$. Los Yanomami de las tierras altas no han conseguido entonces 
machetes provenientes de una cadena más o menos directa con los Ye'kwana (regresaremos sobre este punto más adelante, en la nota 8).

Se puede pues decir que tenemos tres períodos de transición relativos a la economía yanomami:

1. - el período de las herramientas de madera y de piedra;

2. - el período de restos de herramientas metálicas;

3. - el período de las herramientas de metal nuevas y en buen estado.

Los dos primeros se asemejan mucho; el aporte de algunos usados instrumentos de metal aumenta probablemente un poco el tamaño de los conucos, pero éstos quedan, según los Yanomami, muy reducidos y ellos siempre dependen mucho, en esta época, de los recursos silvestres ${ }^{6}$. En compensación, la utilización de las primeras herramientas metálicas usadas puede que haya aliviado el trabajo de desmonte; al mismo tiempo se ha emprendido sin duda, según opinan los Yanomami actuales, un trabajo de conuco sobre parcelas con árboles un poco más grandes.

Los Yanomami de hoy están conscientes de que no saben realmente cómo hicieron sus antepasados para cultivar sus huertos, cuando no tenían herramientas metálicas. Saben lo que dichos antepasados les contaron y algunos atestiguan todavía haber visto las herramientas líticas (manapo). No obstante los conucos eran muy pequeños, con superficies reducidas en comparación con los de ahora y contenían muy pocos cultivos. Empezaban con el desmonte de la maleza; para este fin cortaban los bejucos unidos a los árboles con la ayuda de hachas líticas y de sables de madera (hechos a partir de pedazos de palmera chonta). Las dejaban así secarse. Utilizaban luego el sable de madera, llamado fimó, para tumbar (yarikamai) los árboles, pero solamente los pequeños; los más altos no los tocaban. A los árboles medianos, aproximadamente de $15 \mathrm{~cm}$ de diámetro, se les hacía una hendidura con el hacha de piedra, que después se escarbaba antes de utilizar el sable de madera fimó para hacerlos caer una vez secos. Hay que subrayar que los Yanomami dicen que ese trabajo no se realizaba con la ayuda del fuego. Se rompían con la mano las ramas de los árboles bajos y no las de los árboles altos, los cuales eran golpeados con los sables de madera o con piedras para dejarlos secar (rikishiamaì), antes de romperlos con la mano (más tarde ha- 
rían ese trabajo de desmonte y de tala - pëyëz-con el haoa, fragmento de hoja de cuchillo o machete con mango).

En lo concerniente a los árboles más fuertes, solamente los desramaban con una gafa de madera y hacían caer las ramas al suelo (que eran quemadas una vez secas), mientras que el tronco permanecía intacto. El trabajo de derribar árboles más gruesos (kayapamou) empezó cuando consiguieron hachas usadas; se derribaban alrededor de tres árboles por parcela, atacándolos por un lado con un muñón de hacha y por el otro lado con una azuela. En ningún caso eran utilizadas las hachas de piedra en ese trabajo; éstas servían -tal como después los fragmentos de hojas de cuchillos o de machetes con mangos- para cortar los árboles pequeños o para abrir un hueco en un árbol para recolectar miel ${ }^{7}$.

La selección de las parcelas dependía del imperativo de la ausencia de árboles gruesos. Se despejaban superficies llamadas claros (wawëwawë hami), donde no habían grandes árboles que no eran capaces de eliminar. Esos lugares tienen fama de ser fértiles, se trata de un bosque cubierto de maleza poco densa y que ya es una especie de claro: de ahí el nombre wawëwawë o wawëtowë, donde es wawë, claro. No eran conucos grandes.

Algunos piensan que contenía la mayoría de los cultivos importantes, tal como ocumo, plátano, yuca, caña para las flechas, batata dulce, cambures (pareami, faturimi, paishimi), pero en cantidades muy limitadas. También se plantaba algodón en pequeñas cantidades. Otros consideran que poseían muy pocas plantas, entre las cuales la palmera chonta, el maíz, los cambures (pareami, rokomï, paishimi), el aguacate, pero no tenían yuca, ni caña de azúcar ni algodón, que luego fueron transmitidos. Las versiones difieren debido a la edad a la cual se refieren los informantes. Los de mayor edad recordaban que había poco cultivo en los conucos cuando eran niños y que se recuperaron poco a poco a través de las comunidades en contacto con otras más lejanas. Ellos tienen el razonamiento siguiente: “¿Por qué tratar de cultivar muchas plantas si, al no tener herramientas, no podían crear grandes conucos?”.

Cuando los Yanomami de la Parima intercambian por primera vez herramientas de metal -un cuchillo usado y un muñón de hacha-, lo hacen con una comunidad (Katarowëtheri) situada en el este del lado 
brasileño, que tiene contacto con las demás comunidades situadas en Brasil $^{8}$. Se prestan entre ellos esas herramientas, pero todavía los conucos son pequeños comparados con los de hoy: los habitantes son muy poco numerosos; "la región estaba vacía en aquella época", recuerdan ellos.

Las herramientas usadas se conseguirán a lo largo de los años a través de los intercambios y los conucos se multiplicarán. El fenómeno se manifiesta primero en Parima A donde las comunidades están más cerca de Brasil, y por tanto más cerca de la fuente de abastecimiento de las herramientas de metal. En Parima B se seguirá durante mucho más tiempo trabajando con la ayuda del hacha de piedra y del sable de madera, puesto que las herramientas usadas no les llegan en cantidades realmente suficientes. La sustitución de las herramientas líticas por las metálicas se hizo entonces muy progresivamente, y algunas familias todavía las han seguido usando después de la llegada de las herramientas metálicas nuevas.

Las hojas de piedras ${ }^{9}$ provienen de ciertos saltos de agua donde se consiguen ya pulidas. Estaban atadas sobre mangos de madera de palmera chonta por ser una madera dura, se afilaban sobre pedazos de cuarzo muy cortantes llamados kakuruma. Según un testigo visual cada hogar poseía un hacha de este tipo.

El conuco inicial era muy pequeño, lo ensanchaban luego por los lados para ampliarlo. Cuando, sobre las viejas parcelas, habían crecido otra vez árboles salvajes y antes de que llegaran a una altura elevada se creaba de nuevo un conuco. Este procedimiento podía repetirse varias veces. En efecto, no teniendo herramientas de metal nuevas los Yanomami de la Parima hacían sus conucos sobre viejas plantaciones. Allí cortaban los retoños a mano y los pequeños árboles con gruesos trozos de piedra conseguidos en lugares rocosos. Es probable que establecieran menos conucos que hoy en día, pero dedicaban más tiempo al desbrozo ${ }^{10}$.

Los Yanomami contradicen entonces la idea corriente de una agricultura que sea pionera o seudo-pionera (pues la ausencia de utilización durante un período de más o menos 30 años de las antiguas parcelas permitiría la regeneración del bosque climácico ${ }^{11}$ ) en la Amazonía. La razón se debe, y tendremos confirmación de ello luego, a que la región es muy infértil. Los suelos no convienen bien para la horticultura; los Yanomami 
subrayan el hecho de que el bosque ha sido siempre "malo", o en otras palabras "seco" (fëwë). Así mismo las sabanas de gramíneas ya existían" cuando llegaron y ya había sabanas de helechales.

En estas condiciones uno puede preguntarse ¿̨por qué no migraban? En realidad, no podían ir a instalarse donde existían zonas más fértiles: sus vecinos shamatari que los hostigaban les impedían dirigirse hacía el Sur o hacia el Oeste. Hacia el Norte, habrían tenido tres días de camino puesto que toda la zona intermediaria resulta infértil. El suelo está cubierto de raíces donde sólo crecen árboles muy altos (Micranda rosii) pero es impropio para el cultivo. En el Este, se encuentran las comunidades de Parima A con el mismo tipo de problemas pues la zona es poco fértil. Los Yanomami de Parima B tuvieron pues que resignarse a vivir en esta región donde, por lo menos, había algunas tierras fértiles alrededor y hacer frente a las presiones belicosas de los Shamatari, quienes fueron los que empujaron a los demás grupos (Shiitari, Kopari, Hokomawë) hacia el Noroeste y al Norte. Ahora es más difícil según dicen, pero en aquella época no había sino dos shapono y han considerado esta región como suya aunque el bosque sea poco favorable para los cultivos.

\section{La abundancia de las herramientas metálicas y los nuevos emplazamientos de los cultivos de conucos}

No es, pues, sino a partir de los años 60 cuando la horticultura actual, la que está siendo observada por los investigadores, contando con herramientas metálicas nuevas y en cantidad suficiente, aparece en las tierras altas de la Sierra Parima. En efecto, en este momento, los Yanomami van a abrir parcelas en zonas de bosque alto, haciendo crecer la superficie de los conucos. Es cuando los brasileños llegan que empiezan a crear conucos del tamaño que conocemos hoy día y que dejan, desde el punto de vista alimentario, de depender de las especies de ñames silvestres (raä̈, shara asho). Antes, siendo pequeños los conucos, ellos dicen que se alimentaban mucho con dichos productos silvestres ${ }^{13}$. Notamos un cambio de técnica en comparación con la tala que acorta de manera considerable el tiempo de trabajo y promueve la explotación de superficies más am- 
plias. Dicho cambio técnico acarrea también un cambio en la escogencia de las parcelas cultivables de los bosques.

Esas prácticas son entonces recientes (despues 1961), sólo se inician a lo máximo unos diez años antes de la estadía de W. Smole en la región. En estas condiciones parece evidenciarse la dificultad de proyectar en el pasado superficies determinadas en 1971 y que son el resultado de una tecnología moderna: las superficies explotadas por persona, el número de personas, y las técnicas han cambiado. En efecto, el cálculo de las superficies está basado además sobre datos demográficos de 1974, es decir, en relación con una cifra " $\mathrm{x}$ " de una época " $\mathrm{x}$ ", sin datos diacrónicos comparativos. Esto significa, tomar hoy la superficie de los conucos, dividirla entre el número de habitantes actuales $y$, proyectando estas cifras sobre el pasado, calcular que en tantos años la explotación para el cultivo de conucos se hizo sobre tantos $\mathrm{m}^{2}$ de bosques. Lo que se quiere mencionar es que desde un punto de vista metodológico, la cuestión demográfico debe manejarse con precaución y que las cifras de un momento " $\mathrm{x}$ " no constituyen una base suficiente para emprender cálculos de esta índole. Por otra parte, hay que tomar en cuenta otros datos tales como la tecnología y la historia de los movimientos de población.

Los Yanomami consideran, pues, la fertilidad de los suelos en relación a la tierra y al tipo de asociación de la flora que ahí se encuentra. Para ellos, las zonas fértiles -ishapina- por excelencia son las zonas de claros wawëwawë, donde la tierra es blanda, es decir, húmeda sin ser demasiado mojada, donde los grandes árboles no crecen. Ahí crecen palmeras enanas (pisãasi hena) y platanillos (arama asina), y tienen muchos bejucos enmarañados en los bordes (wayëwayëma). Estos terrenos no contienen nada de helechales.

En la Parima, ellos corresponden precisamente a los emplazamientos ya utilizados como viejos conucos por los antepasados (yetuha fikari suwëpata), y se encuentran ahí retoños de palmeras chontas, de cambures que no proporcionan sino racimos magros, así como plantas enredaderas tales como batatas dulces (bukomo thothopë) y ñames silvestres (sharö asho, shorefepë). Aunque crezcan árboles (mahatoma), son de tamaño muy reducido. Un poco más abajo, al Sur, esas zonas despejadas llamadas ishapina, 
fértiles, corresponden a las riberas del río Putaco y, en el Noroeste, a las regiones del piedemonte a la altura del alto río Ocamo.

En cambio, el tipo de espacio vegetal llamado feawë, está clasificado por los Yanomami como impropio para cultivos, incluye las zonas pantanosas donde el suelo, particularmente húmedo, es muy fangoso. Allí crecen escasas especies y maleza. En las sabanas de gramíneas, esos pantanos se encuentran recubiertos por helechos arborescentes y palmeras moriche. Dentro del bosque esos lugares corresponden a zonas donde el suelo es pantanoso; se trata de un bosque con un suelo blando lleno de bejucos (kreema, shuoukuma, sheroroasipè), de pequeños árboles delgados que crecen cerrados y llenos de maleza. Allí no se puede cultivar conucos y no se puede quemar nada. No hay ni gramíneas ni helechales.

Veamos ahora las zonas que los Yanomami explotan actualmente para sus cultivos. En realidad, urifi wãritiwë, bosque malo, es el nombre dado a este tipo de bosque. Se trata precisamente del bosque que cubre las colinas de la Parima. Pues la definición de las parcelas utilizadas hoy día por los Yanomami es la de un bosque infértil cuyo suelo es duro, según ellos "malo": "aunque la tierra no sea fértil trabajamos los conucos ya que tenemos hachas". Es un bosque donde crecen grandes árboles (kokoa, narimi) que alcanzan a tumbar gracias a las hachas de metal. Por la presencia de estos grandes árboles, los ancestros no podían utilizar este tipo de bosque llamado "malo" tal como lo hacen los desbrozadores de hoy. "Decimos que el bosque es 'malo' puesto que aunque crezca la yuca, el ocumo, la caña de azúcar, la batata dulce, las matas de plátano no alcanzan buena producción" (notemos que los Yanomami prefieren de lejos los plátanos a los tubérculos).

"Donde no hay grandes árboles, el suelo es blando, fértil", pero "aquí la tierra es seca, dura", los granos germinan en gran cantidad en este tipo de suelos y grandes árboles se reproducen. Es, a juicio de ellos, lo contrario de una zona ishapina -apta para el cultivo- en la cual los grandes árboles no crecen.

No obstante, en este tipo de bosque "malo", los grandes árboles tienen fama de retoñar aún después de un incendio. Se registró el caso en una época (alrededor de 1945), en la que todos los árboles calcinados 
retoñaron: "se encontraban todavía negros cuando uno iba de cacería y luego todo se volvía verde de nuevo".

Es decir que cuando la plantación está abandonada los árboles se reproducen en grandes cantidades en el curso de los años. Aunque el suelo esté seco los árboles logran rebrotar pues éste contiene muchísimos granos: "las semillas no pueden desaparecer, aquí los árboles retoñan muy bien", atestiguan ellos. Afirman también que en todo el bosque -que no está actualmente explotado como conuco- los árboles se renuevan. Aún después de haber sido quemado, el bosque creció efectivamente de nuevo en todos los lugares que no habían sido transformados en helechales. Analizaremos luego los problemas planteados a los Yanomami muy recientemente. Lo que es importante aquí es que este bosque, aunque llamado "malo" en el aspecto de la agricultura, es sin embargo un bosque "verde" (riyë).

Cuando se sube en estas zonas de bosque "verde" sobre las colinas de la Parima, uno se encuentra a menudo en presencia de un bosque de mediana densidad. Se compone de árboles delgados de poca altura. Dicho bosque está localizado preferentemente sobre las cimas de las colinas (pororoi) y de los acantilados: allí la vegetación corresponde a la de suelos más secos. Particularmente impropia para la horticultura se llama fëwëfëwë, es decir "seca" con relación al bosque riyë, verde, donde se practica el desbroce. Esas zonas se encuentran privilegiadas por una transformación en helechales si ocurren varios incendios en el bosque.

Ahora bien, en los alrededores de las sabanas de Parima A y B los Yanomami dicen que el bosque es fëwë, seco.

\section{La formación de las sabanas de helechales y el impacto del fuego}

Se encuentran efectivamente numerosas sabanas de helechales sobre las cimas de las colinas de la Sierra Parima. Su formación se debe sin duda a la acción del fuego, así lo demuestran a veces troncos de árboles calcinados en medio de ellos. Su hábitat favorito son las cimas de las colinas, pororoi, y de los acantilados rocosos.

Los helechales existen desde hace mucho tiempo. Sin embargo los Yanomami convienen en la ampliación de los helechales cerca de sus 
conucos y de su territorio de explotación bajo la acción del fuego. En cambio, sólo pueden atestiguar de la formación de los helechales aparecidos más recientemente y de sus orígenes. La formación de helechales se produce cuando la cima de una colina es sometida, en varias oportunidades, a la acción del fuego. La secuencia es la siguiente:

- transformación del bosque "verde" en bosque de maleza y arbustos impenetrables donde ya están presentes los helechos;

- si el fuego interviene otra vez la vegetación se vuelve seca (fëwë);

- la vez siguiente, se forma un helechal.

¿Cómo se propaga el fuego? Esto ocurre siempre en época de sequía cuando hay fuertes calores, cuando el suelo del bosque está en su punto máximo de desecación. Existen tres tipos de causas de incendio, dos son accidentales, es decir involuntarias, y una no lo es.

1. - Cuando se queman desechos vegetales con el propósito de crear un conuco, si el fuego vuela y sube hacia las pendientes, existe la posibilidad de que se queme una superficie si esta última contiene mucha vegetación desecada, mientras que el mismo bosque verde habrá resistido. Si la franja de bosque que separa la zona desbrozada de una cima ya poblada de helechos es de tipo fëwë, es decir desecada (bajo la acción repetida del fuego en esta parcela o debido a un incendio accidental), puede quemarse y luego no retoñar: en este momento los helechos ganan terreno.

2. - El fuego puede igualmente escaparse y propagarse cuando se utiliza dentro del marco de ciertas actividades de cacería o de recolección. Este caso se produce en la estación de sequía y cuando el bosque es de maleza. Los Yanomami utilizan, en efecto, el fuego para ahuyentar las avispas de su nido con el fin de poder sacarlo sin riesgo de ser atacados. Pueden igualmente incendiar la maleza para cazar el cachicamo que se esconde en ella.

Existen muchos ejemplos de superficie de bosque y de helechales ya formados que han sufrido ese tipo de tratamiento. Esto contribuye a su crecimiento y puede haber favorecido la creación de ciertas extensiones de helechales sobre las cimas. Pero también en varios lugares reportados como quemados, la selva creció de nuevo.

3. - Finalmente todos los incendios de bosque no se provocan sin intención. Hay un incendio de bosque al que se refieren los Yanomami 
que remonta alrededor de 1955 . Se trata de un ciclo de venganza ejercido entre comunidades. Unas incendiaron el bosque de las otras para destruir sus cosechas de una especie de fruta silvestre; una vez acabado el incendio los segundos hacen lo propio. El resultado fue muy negativo debido a que el fuego se propagó a todo lo largo de la Sierra Parima, puede ser hasta Simawaroche, por lo que se puede reconstituir con las informaciones obtenidas al respecto. Su amplitud y difusión constituyen sin embargo un caso de excepción que ha marcado la memoria de los Yanomami y, aparentemente, de igual manera, la de los Sanïma. El bosque verde ha retoñado, afirman ellos. No obstante es patente que toda la franja fronteriza desde las cabeceras del río Orinoquito hasta el territorio habitado por los Sanïma está recubierta por sabanas de helechales que se extienden sobre las cimas. Eso es una constatación, pero ¿cómo saber cuál era la situación antes de este incendio? Notemos igualmente que esto no tiene relación alguna con la creación de las sabanas de gramíneas.

Se observa que el factor climático es aquí muy importante. Los años de grandes sequías son propicios para los incendios de bosque. Está claro que el fuego provoca más o menos estragos y se propaga más o menos según el grado de humedad del suelo del bosque. Por ejemplo, el suelo puede quemarse sin que se quemen los árboles, cuando en condiciones de sequía acrecentada, los mismos árboles se consumirán. Por otra parte, cuanto más se suceden las sequías, más lenta es la regeneración, tal como lo veremos luego.

En cuanto a las sabanas de gramíneas, cuya formación es enigmática, los informantes insisten en decir que siempre han existido. Reconocen que las sabanas actuales podrían haberse ampliado en sus orillas. Toman por ejemplo, precisamente, la sabana de la pista de aterrizaje de Parima B e indican los lugares de implantación de las casas de los agentes externos que trabajan en el lugar. A decir verdad, generalmente ellos no notan mucha diferencia en la mayoría de las sabanas que no les parecen haberse ampliado. Cuando un fuego de sabana quema en el margen del bosque, es cierto que sólo una franja de algunos metros se encuentra a veces igualmente en llamas. He podido observar un caso últimamente en la sabana de 
Kanoshewë (cerca de la pista de Parima B), donde algunos árboles habían sido calcinados, lo que debería permitir a la sabana ganar terreno si el bosque no renace lo suficientemente rápido. Sin embargo, la superficie en referencia era menor.

El único caso de sabana compuesta en su mayoría de helechales que se habría transformado en sabanas de gramíneas, todavía se encuentra en un estado de transformación intermedia. Contiene otra especie de helechos (akroewema), más corta de la que compone los demás helechales, así como gramíneas. Pero esta sabana existe desde que los habitantes están en la región. Se trata de una muy pequeña sabana situada al Oeste, no muy lejos de la sabana de la pista de Parima B, y se encuentra al lado del único caso de real transformación de conuco en sabana de gramíneas que se puede observar sobre el terreno. Este caso es totalmente reciente y no concierne de ninguna manera al tipo de agricultura de los Yanomami.

\section{La situación contemporánea}

La situación hoy por hoy de la Parima A y B dista mucho de ser armoniosa. La capacidad de carga de este ecosistema de bosque/sabanas llegó evidentemente a un punto crítico. Actualmente, los Yanomami están conscientes de no dejar rehacer cultivos sobre parcelas recientemente usadas, y que el bosque se vuelve cada vez peor. Así lo comentaba en 1995 un informante de Parima B: "las semillas de los árboles tienden a desaparecer y por lo tanto no pueden crecer. En este momento aparecen zonas de malezas feawë. Este proceso se debe al hecho de que ellos han permanecido en esta región desde mucho tiempo. Entonces los helechos invadieron los conucos. Ahora, en todas partes el bosque se ha vuelto muy malo, ya que los Yanomami son numerosos"..."Aunque hayan existido grandes árboles vivos, ahora, por causa de la formación de muchos helechales, nos sentimos despojados". [Añaden:] "Ahora, nos preguntamos ¿dónde vamos a hacer nuestros conucos? y estamos sumidos en una gran preocupación”.

Usualmente, los Yanomami de la Parima hacen un conuco por año. Lo conservan en explotación por dos años, resultando que cuando un desbrozador abre una parcela, existen ya otras dos en uso. Al tercer 
año, la más antigua de las tres (A) queda abandonada, las siguientes (B) y (C) todavía están en producción, una parcela (D) se abre etc. En resumen, cada hombre adulto posee dos conucos en producción ${ }^{14}$.

En dos años, el bosque retoña en una parcela abandonada; y en tres años, ya los árboles han adquirido altura. Las parcelas abandonadas no son en principio reutilizadas durante muchos años. Si se procede a cultivar sobre un conuco viejo de manera demasiado frecuente, los helechos lo invadirán y el desbrozo será imposible de realizar. Los nuevos conucos se realizan en principio en el bosque "verde" y no sobre el antiguo conuco.

En esta región de colinas, los Yanomami abren sus conucos en los valles en forma de "V", que pueden estar más o menos abiertas en su fondo donde brotan manantiales, pero igualmente sobre los planos de una pendiente. Pueden igualmente hacerlos sobre el lugar de antiguas plantaciones abandonadas desde hace muchos años en las colinas o sobre las riberas de los ríos. Utilizan estas parcelas durante dos años cada una antes de abandonarlas. Actualmente los Yanomami abren pues en este bosque que ellos llaman "malo", donde crecen grandes árboles (de manera general, los lugares fértiles no tienen árboles de madera dura), ya que tienen hachas para derribarlos, pero este bosque es muy seco, las matas de plátano crecen difícilmente en él.

Los Yanomami contradicen así perfectamente la idea según la cual el bosque de altitud es más conveniente que las tierras bajas para la horticultura y se hace manifiesto que el área de la Parima no es exactamente un hábitat preferencial. Haré aquí referencia a la discusión de P. Descola (1986 [1983]) quien muestra en su trabajo que los Achuar contradicen la tesis de E. Roos (1976: 35), según la cual la selva húmeda de altura conviene más a la horticultura de quema que la de las tierras bajas, argumentando que no hay una diferencia suficientemente significativa de fertilidad entre las tierras bajas y el bosque húmedo de altitud. Roos, para sostener que los Achuar prefieren establecer sus conucos en las colinas interfluviales que en las tierras bajas, se apoya sobre W. Denevan (1970: 73, en la Amazonía del Oeste), y Smole (1976: 46, para la Parima). Este último queriendo justificar una preferencia de los Yanomami para la práctica de la agricultura sobre las valles en "V" de las colinas de la Parima, hace en 
efecto referencia, al igual que Denevan, a las tasas menos rápidas de lixivación de suelos que en las tierras bajas y a la invasión menos rápida de las matas adventicias. Descola (1986 [1983: 252]) matiza el segundo argumento de Smole, argumentando en contra de la tesis de R. Carneiro (1961: 57) según la cual es menos la disminución de la fertilidad del suelo que la proliferación de las plantas adventicias que provoca el abandono de las parcelas: el desarrollo de las matas adventicias no es un obstáculo por sí mismo, es la disminución de la fertilidad en los suelos pobres en base a la causa mayor del abandono de las plantaciones ${ }^{15}$. El primer argumento de Smole no tiene mayor fuerza, hay que notar que las laderas de las colinas de Parima pueden estar muy empinadas y, con la supresión de la capa vegetal natural, estar sujetas a un empobrecimiento también rápido de los nutrientes. En cambio, lo que puede variar es la tasa de las precipitaciones, siendo la pluviometría mucho menos importante en la tierras altas que en las tierras bajas, tal como lo señalamos, $O$. Huber y yo misma, en nuestro artículo (Huber et al. 1984). Insistiré sobre el hecho de que el bosque de altitud es aquí definitivamente poco húmedo.

El otro punto esencial es que los Yanomami no escogen realmente los valles en "V" de las colinas de la Parima con preferencia a las tierras bajas. El problema no se plantea evidentemente en estos términos. Por una parte, la utilización de las laderas de las colinas de la Parima es un fenómeno relativamente reciente, es por falta de lugares explotables (por larga permanencia y crecimiento de la población) en las riberas de los ríos, donde fueron originalmente huertos cultivados, que rozan en las partes en pendientes. Dicho en otras palabras, las explicaciones a una ocupación de un nivel ecológico en terminos estrictamente de rentabilidad óptima del ecosistema son reductoras, hay otros factores determinantes por considerar. Se trata de una opción condicionada por numerosos factores, a la vez históricos, sociopolíticos y edáficos, para la cual hemos visto que habían pocas alternativas. Por otra parte, cuando Denevan (1970) argumenta en favor de una mejor fertilidad del bosque de altitud, habla de un piedemonte de más de $800 \mathrm{~m}$ en comparación con un bosque de tierras bajas no aluvial, donde ciertamente hay variaciones de relieve y de condiciones climáticas, pero no en la naturaleza de los suelos. No se compara 
entonces la selva de altura con las tierras bajas aluviales donde el potencial hortícola es sin duda superior a la de la selva de altura (cf. Descola 1986 [1983: 252]). Ahora bien, en el caso que estudiamos, ya estamos dentro de las tierras altas (900 $\mathrm{m}$ de altitud y más), las zonas fértiles indicadas por los Yanomami, citadas más arriba, se sitúan debajo de $800 \mathrm{~m}$, es decir, en el piedemonte de esta área. Eso nos lleva a considerar que se debe tener cuidado de no oponer solamente el bosque de las tierras bajas a la selva húmeda del piedemonte para opinar sobre la rentabilidad de los cultivos, pues tenemos igualmente que tomar en cuenta el caso particular de la selva de las tierras altas donde la lluviosidad es menor. Parece, en efecto, que en aquella región la selva está lejos de disponer del capital de productividad de la selva de las tierras bajas o del piedemonte ${ }^{16}$.

\section{El paso hacia el monocultivo}

Muy recientemente, dos nuevos problemas, ligados entre sí, se presentaron a los Yanomami de la Parima $\mathrm{B}^{17}$. La reutilización demasiado rápida de antiguas parcelas ha favorecido la invasión de estas zonas por los helechos. También han visto allí por primera vez la llegada de gramíneas. En efecto, estas últimas han ganado últimamente bastante terreno: aunque la sabana esté lejos, ellas llegan a los conucos tanto a los nuevos como a los abandonados, aun cuando los árboles están creciendo otra vez. Sin embargo, cuando retoña el bosque en el conuco, tanto las gramíneas como los helechos desaparecen.

"Antes -atestigua un anciano- las gramíneas no crecían en los antiguos conucos, y el bosque retoñaba. Pero hoy día se implantan. Antaño los helechos venían en los conucos; hoy día son las gramíneas las que crecen enseguida”. Este fenómeno jamás visto en el pasado se produjo en 1994. Sin embargo se trataba de un año de particular sequía ${ }^{18}$. El fuego empezó en el bosque y se propagó sobre una gran parte de las colinas que rodean la sabana de Parima B. Los árboles quedaron verdes pero se quemó el suelo. No hay que pensar que no habrá regeneración: el bosque está actualmente retoñando puesto que quedan todavía muchas semillas en el suelo. 
A pesar de lo anterior, el caso de los conucos dentro del mismo sector, que se rehicieron demasiado rápido sobre antiguas parcelas es más preocupante: crecieron muchos helechos y los Yanomami están conscientes de que van a tener problemas a causa de ello.

¿Cuál es la secuencia para esos casos precisos? Digamos que son relativamente restringidos ya que se trata de algunos conucos realizados sobre la orilla izquierda del río que bordea la sabana de la pista de Parima B. Esos conucos han sido sembrados antaño por miembros de los grupos que componían las tres casas colectivas de Niyayopë; han sido explotados en 1980, luego una segunda vez en 1986, y una tercera vez en 1992. Después los helechos han invadido masivamente los bordes y hasta el centro de las parcelas. El mismo caso se produjo en conucos situados al Norte y que han sido re-explotados demasiado rápido. En el borde de los conucos, la franja de árboles secos, luego verdes, es cada vez más reducida y se encuentra cerca de la zona de helechos preexistente. Con toda evidencia esto anuncia las dificultades del bosque para regenerarse.

¿A qué motivo se debe una re-explotación tan frecuente de las parcelas y en qué consiste la diferencia en los hábitos de cultivos para provocar tal cambio?

De hecho, los habitantes de la Parima B se mantuvieron en este sitio de manera artificial por la presencia de la misión. El resultado fue una cohabitación inusual de personas que se habrían separado y también alejado desde hace mucho tiempo dentro del cuadro de los cánones tradicionales ${ }^{19}$. Queda patente que la concentración numérica, entre todas las aldeas satélites de la misión, es demasiado importante en relación con la capacidad de carga del ecosistema. Al crecimiento demográfico se añadió el agotamiento de las reservas de cacería y de tierras cultivables que la falta de movilidad de los grupos ha provocado. Además los últimos años (a partir de 1988) han sido años en los que las epidemias se manifestaron de la manera más fuerte. Los grupos se debilitaron, fenómeno que no es ajeno a la invasión del territorio Yanomami por los garimpeiros brasileños ${ }^{20}$. Esta mala situación, junto con las dificultades locales de coresidencia, la falta de recursos cinegéticos y agrícolas, más la radicación del ejército en Parima B a partir de 1991, radicación ella misma vinculada a la presencia 
ilegal de los garimpeiros, han favorecido en 1992 un proceso de dislocación de las comunidades implantadas en la sabana de Niyayopë, así como de las de la sabana de Ishawari que queda al Sur. Esto ha dado lugar a una relocalización dispersa en 25 pequeñas casas colectivas más al Norte y, respectivamente, al Sur.

No obstante el momento en el que las comunidades de Niyayopë se han dividido, coincidió con el momento en que han experimentado otro modo de cultivo. Han sembrado grandes conucos de yuca y al mismo tiempo han desbrozado cantidades suplementarias de parcelas.

Ahora bien, no se trata, allí, de técnicas yanomami, los cuales son policultivadores. Se sabe que el policultivo está mejor adaptado a este tipo de ecosistema que el monocultivo, puesto que este último favorece una lixivación más importante de los nutrientes de los suelos. En cambio, la primera agota menos los suelos por tener una vegetación estratificada, debido a la combinación de plantas de diferentes alturas en un mismo lugar (como musáceas/yuca/ocumo), que protege la capa fértil del suelo de la insolación, así como de las lluvias ${ }^{21}$ y favorece el retoño de la selva y su regeneración ${ }^{22}$. En lo que se refiere a ese nuevo modo de explotación de parcelas, su re-explotación, así como el desbroce intensivo, los Yanomami fueron influenciados y tomaron ejemplo de una familia de empleados ye'kwana establecida en Parima B. La apertura a la siembra de yuca de vastas zonas reservadas fue una reacción a la escasez repetida de comida cultivada, y se pensó que la yuca podría dar un mayor rendimiento y más seguridad por su potencial de conservación que los plátanos ${ }^{23}$.

En los conucos de yuca situados al lado derecho del río Niyayopë que bordea la sabana de la pista Parima B, han desbrozado en varias oportunidades. Aún en el momento de la recolección, siguen desbrozando. Pero lo que es importante subrayar es que dentro de este cuadro el desbroce no consiste en cortar las matas adventicias así como la vegetación secundaria que retoña: los jóvenes árboles que están creciendo son igualmente arrancados, sacados de raíz. Eso explica la razón por la cual empiezan a implantarse los helechos cuando la superficie se encuentra completamente limpia. Más tarde, cuando la parcela ha sido abandonada por dos años, los helechos crecen masivamente. Así es como últimamente, en 1993 
y 1994, se han visto conucos de antaño totalmente regenerados en forma de bosque, transformarse en helechal en detrimento del retoño de árboles. Dicha ola de "helechalización" de ciertos conucos corresponde a varios factores:

- a la re-explotación demasiado frecuente de las parcelas - 6 años en lugar de 10 a 12 como lo hacían antaño;

- a una re-explotación desgraciadamente ligada a una sucesión de años de sequías particularmente fuertes;

- a un cultivo intensivo de yuca con una técnica de desbroce nueva: destrucción de los retoños de árboles, lo que impide en consecuencia la regeneración del bosque a favor de la aparición, por una parte, y la instalación, por la otra, de los helechos sobre el conuco una vez abandonado, es decir, la transformación de las parcelas en suelos estériles.

Sin embargo, cuando hay helechos en las franjas de los conucos pero la vegetación silvestre retoña después que estos últimos han sido abandonados y que los árboles crecen otra vez, los helechos desaparecen.

¿Cuál es el modelo de monocultivo que han imitado? En el caso de las plantaciones de la familia ye'kwana, las parcelas, situadas sobre la misma ribera, son sucesivamente reutilizadas durante 5 años, con la actividad de limpieza repetitiva de maleza que ello supone para obtener tal resultado. Hasta 1995, sobre un período de más de 20 años, hubo 7 parcelas abiertas en su totalidad; 4 de ellas están totalmente abandonadas y tres todavía en explotación. Se constata en este caso que el bosque no volvió a crecer en la primera parcela, ni en ninguna otra de las parcelas siguientes que se quedaron sin cultivo desde hace años. Ahí crecen los helechos y, en particular, se han formado dos extensiones de gramíneas.

El espacio liberado en la parte trasera de una parcela no es utilizado para el cultivo, pero ha sido desbrozado y quemado al mismo tiempo que el conuco: sirve de reserva de madera para cocinar. Pero en el momento en que está desbrozado, los retoños de árboles se arrancan: una vez libre de sus semillas de árboles que se encontraban dentro del suelo y podían regenerar el bosque queda como lugar privilegiado de implantación de los helechos. El bosque no vuelve, los helechos alcanzan el plano dejado libre y crecen en su lugar. Aquí, así mismo se encuentran gramíneas que han crecido en dos lugares por contaminación debido a la preexistencia de una 
pequeña sabana de gramínea situada inmediatamente encima de los conucos. La franja de bosque que separa los conucos de esta sabana se redujo a medida que se repetía la creación de parcelas en este mismo lugar. Como resultado, los árboles en el borde se han desecado bajo la acción del fuego, y los árboles verdes que los separaban de la sabana han desaparecido a tal punto que las dos sabanas de gramíneas, la antigua y la nueva, se han ido juntando.

Ese caso de formación de sabana de gramíneas es único en toda la región de Parima A y B. Se debe a un uso intensivo de las parcelas, a un modo de explotación correspondiente al cultivo de la yuca, el cual exige un tipo de desyerbe particular, y a la creación de parcelas contiguas durante más de 20 años en un mismo lugar, lo que hace de esto un caso especial. Resulta de una situación exógena a la cultura yanomami debido al establecimiento de la misión en Parima B y de la implementación consecutiva de empleados para los servicios sanitario y escolar. Esta explotación tampoco sigue los cánones tradicionales en el sentido de que no está sólo destinada a un consumo familiar, sino a la obtención de una sobreproducción de yuca dirigida a la venta local en forma de mañoco para los Yanomami. Esta misma se obtiene empleando una mano de obra excepcional de hombres y mujeres yanomami que realizan las tareas de rozo, de desbroce, de cosecha y ayudan a todo el proceso de tratamiento de rallar y transformar la yuca en mañoco.

En resumen, se necesitan pues condiciones muy particulares para que un conuco se transforme en helechal, y aun en sabana de gramíneas. Eso supone condiciones especiales:

1. - en la explotación de los suelos, es decir, una rotación insuficiente;

2. - en el tipo de cultivo y técnicas afines: aquí, la yuca y el desyerbe en profundidad, lo que favorece un lavado más profundo de los nutrientes del suelo;

3. - en los regímenes climáticos, es decir, años de mucha sequía favorable para los incendios y la propagación del fuego (durante estos años las plantaciones tienen un crecimiento muy débil (ver la nota 19); 
4. - en los caracteres edáficos: el suelo del bosque es malo, puesto que está seco y duro;

5 - en la permanencia humana: instalación persistente, lo que favorece a la vez una utilización intensiva de los mismos hábitats, pero igualmente la explotación extensiva de nuevos sitios, impropios para los cultivos.

Como ya lo hemos visto, el único caso de transformación de bosque en sabana de gramíneas registrado en Parima B es el ejemplo del espacio trasero de antiguas plantaciones del personal ye'kwana que se encuentran del lado derecho del río Niyayopë.

Para concluir, la explotación excepcional del sitio de Parima B, tiene un impacto real negativo de más de 25 años. Hubo una sobre-explotación y además ella se hizo dentro del cuadro de condiciones climáticas específicas. Se trata pues de la confluencia de varios factores a la vez históricos, sociológicos (sedentarización influenciada, añadida a una concentración humana no tradicional, intervenciones externas), técnicos (introducción del hacha de metal, más cultivo intensivo de yuca), climáticos (sequía con fuego accidental), además de prácticas forzadas de sobre-explotación de las parcelas (aceleración de la rotación), que terminó de provocar una transformación del paisaje jamás visto en 30 años de permanencia.

Sin esos factores conyunturales, el bosque retoña y ya ha retoñado en varias oportunidades.

Es el papel de los pedólogos explicarnos la razón por la cual el bosque es frágil en esos lugares. Pero nos incumbe a nosotros declarar que el impacto humano yanomami es finalmente mínimo a pesar del ejemplo de una explotación continua y forzada durante una treintena de años. Debemos tener en cuenta que este modo de explotación es de origen exógeno, y que no corresponde al modo propio de explotación y utilización del medio de los Yanomami. En lo que concierne a la creación y formación de sabanas, tenemos seguramente que analizar factores distintos al factor antropogénico, el cual es el elemento esencialmente subrayado en ciertas presentaciones.

Deberíamos igualmente interrogar la arqueología para comprender el modo de explotación del medio por las poblaciones más antiguas 
que se han establecido en las sabanas de Parima y del alto Ocamo. Se encontraron en 1991, al momento de la extensión de la pista de aviación de Parima B por el ejército, numerosos fragmentos de alfarería enterrados en un antiguo sitio de ocupación en la sabana (J. Chiappino \& C. Alès 1991). Dichos fragmentos pertenecen a una cultura diferente a la que ocupa actualmente esos lugares. Se trata, en efecto, de una alfarería mucho más sofisticada que la alfarería yanomami, probablemente de origen arawak. Se consiguen vestigios similares de alfarería a cielo abierto en la sabana situada a la altura de la confluencia del río Putaco y del Ocamo medio. Ahora bien, se nota igualmente la presencia de yopales en el borde de la sabana lo que sería congruente con la estadía de una población arawak $^{25}$. Se puede pensar por ejemplo que los Guinau, un grupo arawak, provienen de esas regiones. Se encuentran actualmente reducidos a unos cuantos y han sido fagocitados por la cultura ye'kwana, aunque como lo señala N. Silva (comunicación personal, 1995) su origen distinto quede marcado localmente.

Esta es la razón por la cual se debe pensar que la formación de sabanas de gramíneas tendría un origen muy antiguo, y estaría relacionada a una serie de factores dentro de los cuales los factores edáfico y climático deben haber tenido un papel determinante en relación al factor antropogénico. Según lo que se sabe hoy por hoy acerca del modo de explotación del territorio por los indígenas, se espera haber demostrado que éste no es la causa de la formación de sabanas de gramíneas. Quizás habría que pensar que éstas se han instalado probablemente sobre suelos impropios para conservar el equilibrio forestal. El bosque amazónico no es en todas partes un bosque denso y húmedo dotado de una exuberante vegetación aprovechando una higrometría ideal para su conservación y regeneración. La naturaleza de los suelos y las condiciones climáticas difieren y, en este sentido, las de las tierras altas de la sierra Parima no parecen haber sido propicios para la existencia de un bosque rico y fértil. Por el contrario se encuentra en todas partes un bosque seco, "malo", como dicen los Yanomami y las especies de árboles que allí crecen se diferencian de las que se encuentran en el piedemonte o en las tierras bajas. En comparación existen pocas palmeras, los bananos no crecen bien así como 
todas las plantas que necesitan de suelos blandos y húmedos. En esta dirección podría ser interesante orientar más las investigaciones en lugar de resolver rápidamente el asunto, en el cual debemos también evitar el riesgo de tomar los efectos por las causas, cuestionando siempre el modo de vida indígena.

\section{NOTAS:}

${ }^{1}$ Según los misioneros de las Nuevas Tribus, este autor permaneció seis semanas en Parima B en 1971, cuando ellos mismos habían llegado recientemente al lugar, y recogió sus datos por conducto de ellos (W. Jank, comunicación personal, 1980).

${ }^{2}$ También existen zonas de sabanas en las áreas vecinas al Noroeste que se observan, por ejemplo, cuando uno sobrevuela de la Parima B hasta Puerto Ayacucho.

${ }^{3}$ Para una descripción detallada de la técnica de agricultura y una lista de las plantas cultivadas por los Yanomami, ver el artículo de J. Lizot (1980). Sobre la problemática de la agricultura entre los Yanomami, ver también N. Chagnon 1968, M. Colchester 1981.

${ }^{4}$ Dijeron que venían de los “napë pë nï”, es decir, de "los extranjeros", quienes podían ser los propios Ye'kwana o misioneros.

${ }^{5}$ Los Yanomami no hacen guerra para obtener herramientas metálicas, cuando ocurre que consiguen una herramienta en la ocasión de una incursión es siempre un beneficio secundario, pues se encuentra al alcance de uno (Alès 1984b, 1993). Y los casos son escasos. En un libro sobre el tema de la guerra entre los Yanomami, B. Fergusson (1995), conjetura que el aprovechamiento de herramientas metálicas es el motivo esencial para los Yanomami del cumplimiento de incursiones a otros pueblos y de la intensificación de aquéllas. En realidad, su argumento está basado sobre datos seleccionados y parciales, recopilados en otros autores, y la intensificación de la guerra es igualmente presupuesta. Lejos de tratar de manipular a los antropólogos que trabajan en el campo, tal como lo pretende este autor, los Yanomami niegan firmemente su tesis, así como lo hacen los numerosos datos de campo sobre los cuales está basado el análisis de los motivos de guerra y del sistema global de agresión-defensa entre los Yanomami que presenté (cf. Alès 1984b, 1993). Este análisis corresponde a varias incursiones observadas y a múltiples casos de guerras contemporáneos o históricos reportados por los informantes, incluso antes de la llegada de herramientas de origen occidental. No son entonces muy escasos, tal como lo escribe Fergusson, los datos sobre la guerra en la Sierra Parima.

${ }^{6}$ Eso puede explicar por qué los primeros viajeros reportan más bien a los Yanomami en campos de selva y aparentemente sin cultivos y que fueron clasificados al principio como cazadores-recolectores. 
${ }^{7} \mathrm{Al}$ contrario de lo que se observa entre las comunidades del piedemonte o de la penillanura, el instrumento haoa hecho a partir de un fragmento de hoja de machete amarrado en su centro a un mango de madera, no ha desaparecido de las tierras altas de la Sierra Parima después de la introducción de los instrumentos metálicos nuevos: su fabricación sigue todavía vigente. Este se utiliza para diferentes usos, entre los cuales el más notable es para abrir los árboles para extraer la miel. No obstante, los primeros haoa eran muy pequeños, hechos con fragmentos de cuchillos; se diferencian de los grandes haoa, los que usan hoy en día y que se harán sólo cuando llegaron los machetes nuevos.

${ }^{8}$ Estaban también en contacto con los Shitoyotheri y probablemente las herramientas usadas venían por intermedio de los Maithatheri o de las comunidades de la región de Surucucu. Según P. Birreaux (1992: 28), estas últimas comunidades obtuvieron las primeras herramientas manufacturadas por intermedio de los Maithatheri, que vivían a $60 \mathrm{~km}$ al Norte de Surucucu, vía los Parimitheri, los cuales las obtenían a su vez de sus vecinos Mayongong (Ye'kwana), ellos mismos viajeros hasta Boa-Vista (e incluso Manaus, según N. Arvelo Jiménez) por el Uraricuera. Del lado venezolano, según M. de Civrieux (1970: 11-14), los Ye'kwana han podido tener algunas veces herramientas de acero después de 1764.

${ }^{9} \mathrm{El}$ material lítico era diverso y no se encontraba en todas partes; era utilizado también diferentemente para usos como el rozamiento, la leña, la miel o los combates. Hay por lo menos dos tipos diferentes de hachas de piedra, las piedras pulidas encontradas en el suelo, que son testigos de antiguas poblaciones -éstas se encuentran todavía y sirven para moler las substancias alucinógenas en las sesiones de chamanismo-, y las piedras elegidas en los ríos y afiladas por los Yanomami. Los Yanomami de la Parima recuerdan más bien estas últimas para el cultivo. Ellas podían ser pequeñas y otras más gruesas; las raspaban sobre las rocas del río para hacer dos encoches de manera de poder amarrarlas. Eran de aproximadamente 15 $\mathrm{cm}$ de largo y $5 \mathrm{~cm}$ de ancho. Las que eran lisas las reservaban para los combates. Llaman las dos manapo. Las caídas de aguas en las cuales se encuentran son pocas, así que no todas las comunidades las tenían. Se las prestaban al igual que los instrumentos metálicos. Para obtener la miel en los árboles o talar los pequeños árboles y los bejucos, también usaban lo que llaman poo, piedras gruesas pero cortantes tomadas de las rocas, que no estaban amarradas a un mango.

${ }^{10}$ Antes las herramientas métalicas, desbrozaban más pero abrían menos conucos; luego la facilidad de la tala provoca que los conucos demoraran menos tiempo en explotación: se abren más conucos pero se desbrozan menos. En Nueva Guinea, se ha comprobado que así se divide el tiempo de trabajo de tres, tres y medio (cf. Salisbury 1962: 112-122, Godelier 1964) a cuatro veces (cf. Godelier \& Garanger 1973: 218). Los Achuar de Ecuador estiman muy generalmente que la economía de tiempo traída por las herramientas de metal es del mismo orden de la que fue emitida por la Nueva Guinea (cf. Descola 1986, [1983: 257]). 
${ }^{11}$ Según Schnell (1972 [2]: 694), la reconstitución completa de la selva densa húmeda exige varios siglos, pero Sastre (1975) dice que luego de algunas décadas la selva está reconstituida y tiene de nuevo una composición que se aproxima a la del bosque climácico. Es imposible, un siglo luego un conuco, de distinguir el bosque primario del secundario; treinta años más tarde, la vegetación se estructura como un bosque climácico (cf. Descola 1986 [1983:190]).

${ }^{12}$ No son así tanto "newly created secundary savannas", tal como está sugerido en el artículo de Huber \& Zent (1995: 56).

${ }^{13}$ Todavía pueden comer hoy en día de éstos cuando los conucos están demasiado jóvenes o luego de haber agotado sus reservas de plátanos cuando permanecen en campos provisionales en la selva.

${ }^{14}$ Las superficies de los conucos de altitud son menores que las de la penillanura, pero en Parima se abre una parcela por año mientras que, aparentemente, las comunidades situadas cerca del Orinoco abren una parcela cada dos años. Esto daría el mismo orden de superficie cultivada en ambos casos (por ejemplo, Smole, 1976: 136, da parcelas de 405 y $607 \mathrm{~m}^{2}$ para Parima, y Lizot, 1977: 127, de $900 \mathrm{~m}^{2}$ para los Yanomamï centrales).

${ }^{15}$ Los Yanomami dicen que debe desyerbarse de la misma forma-debajo de las matas de yuca y de ocumo- tanto en los conucos sobre las pendientes, como en los que se encuentran en las partes llanas de las riberas.

${ }^{16}$ En esta discusión no se puede pensar que sólo hay unos pocos tipos de vegetación y de suelos en toda la Amazonía. Todavía falta mucho por aprender de los estudios sobre la diversidad de los ecosistemas y de los tipos de suelos presentes en la Amazonía.

${ }^{17}$ Se trata de las comunidades implantadas al norte de la pista de aviación Parima B, situadas en las sabanas de Niyayopë, Kanoshewë, Okiyamopë y Hawatokoi.

${ }^{18}$ Los años 1990-1991 fueron de epidemias de paludismo en toda la región. Hizo un clima especialmente seco, las matas no crecían en los huertos y resultó que los Yanomami pasaron hambre y sufrieron mucho. En 1992-1993, aunque el suelo tenía un poco más de humedad, las plantaciones no crecieron bien. El año 1994 fue de especial sequía, todo el bosque estaba seco. Cuando un fuego se declaró, una vasta zona se incendió a nivel del suelo aunque los árboles se quedaron verdes. Cuando hay condiciones de mayor humedad, tales fuegos no se propagan. 1995 fue un año con buenas condiciones de humedad. Hay que hacer notar que las variaciones climáticas de un año a otro son muy importantes, las cosechas de una fruta silvestre pueden variar, por ejemplo de uno a tres meses, y se conoce aparentemente cíclicos años de gran sequía; a veces hay condiciones secas varios años consecutivos. Eso es entonces un factor esencial para tomar en cuenta en la problemática de la propagación de los fuegos accidentales y en la alteración consecutiva de los bosques. Además, si los años donde las condiciones climáticas son más secas están seguidos por un régimen más húmedo que de costumbre; el impacto de 
lluvias importantes puede también ocasionar, con el endurecimiento de los suelos, un efecto devastador.

Nota adicional: desde 1997-1998, se conoce más por la virulencia registrada, el fenómeno climático llamado "El Niño". Así se puede pensar que hay una posible relación con las sequías cíclicas que se notaron en aquella región. Se sabe que se manifestaron seis Niños desde 1972 (en 1972, 1976, 1982, 1986, 1991, 1997). En 1997-1998, incendios gigantescos se declararon en el norte de Brasil en los bordes del territorio yanomami. Independientemente de los incendios internacionalmente reportados, surgieron fuegos, alrededor de Parima B, al interior mismo del bosque, varios días después que se terminó la quema de los rozos, y se desarrolló una espesa nube de humo que se quedó de manera persistente a lo largo de varias semanas. Todavía tenemos mucho que aprender sobre estos fenómenos climáticos como el Niño y la Niña y sobre sus influencias en las alteraciones del medio ambiente.

${ }^{19}$ Se fueron un momento a instalarse a un día de camino al Oeste, pero los misioneros los convencieron de regresarse a las sabanas de Parima B. Los Yanomami están conscientes de que si no hubiera pasado así hace mucho tiempo que hubieran abandonado el lugar y migrado hacia el Oeste y de allá hacia el Noroeste al interior del bosque.

20 En un artículo reciente, O. Huber y S. Zent (1995: 57), sugieren que la actual concentración de la población Yanomami en Parima está favorecida por la presión ejercida por los garimpeiros brasileños, especialmente a lo largo de la serranía brasileña de Parima, quienes obligan a muchos grupos yanomami a retirarse hacia las tierras altas de Parima. En realidad la situacion actual es sólo el resultado de la dinámica demográfica de los Yanomami. De hecho, los garimpeiros no han influenciado numerosos desplazamientos y concentración de habitantes hacia la Parima, y la población actualmente presente en la Parima es sólo el efecto del crecimiento natural de las poblaciones que previamente vivían en el área. Más bien la invasión garimpeira y la intensificación de los contactos y movimientos exógenos han causado muchas epidemias y enfermedades que elevaron la taza de mortalidad de los Yanomami del área. Pero eso contribuye a decir que la situación de presión sea más importante en esta zona. Es la razón por la cual sería entonces problemático establecer una base administrativa, como una parroquia, por ejemplo, en el marco del nuevo municipio Alto Orinoco, lo que inevitablemente reforzaría la sedentarización e instalaciones suplementarias, en el sitio ya en estado crítico de sobrecarga de Parima B.

${ }^{21}$ Para una discusión sobre las potencialidades agrícolas de la selva amazónica ver $\mathrm{H}$. Sioli (1964, 1973), E. Morán (1982, 1993), P. Descola (1986), N. Arvelo Jiménez (1983: 105-107).

${ }^{22}$ Eventualmente obliga también a un abandono más rápido de las plantaciones (R. Carneiro 1961, Harris 1971: 481), punto discutido por Sánchez (1976: 377$378,405)$. 
${ }^{23}$ Esta reacción tiene relativas similitudes con el caso descrito por J. Frechione (1983: 64), por ejemplo, de los Ye'kwana de Asenöña en el alto Ventuari, donde la escasez de yuca (relacionada también con la sequía o un exceso de lluvia) contribuyeron aparentemente a un crecimiento de la práctica de la yuca en "monozonamiento". Se ve así que la plantación de yuca sobre considerables superficies es también reciente entre los Ye'kwana. Sobre la agricultura ye'kwana, el policultivo y el monocultivo, ver también R. Hames (1983).

${ }^{24}$ En muchas de las sabanas de Parima A y B, se encuentran árboles Anadenanthera peregrina (o Piptadenia peregrina) que no fueron sembrados por las poblaciones yanomami actuales.

\section{REFERENCIAS:}

Alès, C. (1984a) "Notes on The Yanomamï of Sierra Parima and their Environment", in "The Vegetation of The Sierra Parima, Venezuela-Brazil: Some Results of Recent Exploration”, Brittonia 36 (2): 132-136.

(1984) "Violence et ordre social dans une société amazonienne. Les Yanomami du Venezuela", Etudes Rurales 96-97: 89-114.

(1993) "Violencia y orden social: Conflictos y guerra entre los Yanomami de Venezuela", Folklore Americano 55: 75-106.

Alès, C. \& J. Chiappino (1994) «Les stratégies locales des Yanomami face au changement», ponencia en el simposium «Settlement, Substistence and the Conquest of South America: Ongoing Threats to Indigenous Cultures», Stephen Beckerman \& François Picon organisadores, IIL International Congress of Americanists, 4-9 Juillet, Uppsala/Stockholm.

Arvelo Jiménez, N. (1983) «Recursos humanos o el juego de fuerzas en la región amazónica», en El Universo amazónico y la integración latinoamericana, Universidad Simon Bolívar, Instituto de Altos Estudios de America Latina: 103-115.

Birreaux, P. (1992) «Les Yanomami, la forêt et les «Blancs», Géographie et Cultures 4: 25-34. Carneiro, R. (1961) «Slash-and-burn Cultivation among the Kuikuru and its Implications for Cultural Development in the Amazon Basin», in J. Wilbert (ed.), The Evolution of Horticultural Systems in Native South America: Causes and Consequences: 47-64. Caracas: Sociedad de Ciencias Naturales La Salle.

Chagnon, N. (1968) "The Culture-Ecology of Shifting (Pionnering) Cultivation among Yanomamö Indians", Proceedings VIII International Congess of Anthropological and Ethnological Sciences 3: 249-255.

Chiappino, J. \& C. Alès (1991) "Informe sobre un sitio arqueológico en el territorio yanomami (Sierra Parima)", remitido a la DAI, Caracas, en octubre 1991, ms.

Civrieux, M. de (1970) Watunna. Mitología Makiritare. Caracas: Monte Avila Editores. 
Colchester, M. (1981) “Ecological Modelling and Indigenous Systems of Ressource Use”, Antropologica 55: 51-72.

Denevan, W. (1970) "The Aboriginal Population of Western Amazonia in Relation to Habitat and Subsistence", Revista de Geográfica 72: 61-86.

Descola, P. (1986) La Nature domestique. Symbolisme et praxis dans l'écologie des Achuar. Paris: Fondation Singer-Solignac/Editions de la Maison des Sciences de l'Homme. [1983] Thèse de Doctorat, EHESS, Paris.

Fergusson, B. (1995) Yanomami Warfare: a Political History. Santa Fé: School of American Research Press.

Frechione, J. (1982) “Manioc Monozoning in Yekuana Agriculture”, Antropológica 58: 53-74.

Hames, R. (1983) "Monoculture, Polyculture and Polyvariety in Tropical Forest Swidden Cultivation”, Human Ecology 11 (1): 13-34.

Harris, D. R. (1971) "The Ecology of Swidden Culture in the Upper Orinoco Rain Forest, Venezuela", The Geographical Review LXI (4): 475-495.

Huber, O. \& S. Zent (1995) Indigenous People and Vegetation in the Venezuelan Guayana: Some Ecological Considerations”, Scientia Guaianae 5: 37-64.

Huber, O., J. A. Steyermarck, G. T. Prance \& C. Alès (1984) “The Vegetation of the Sierra Parima, Venezuela-Brazil: Some Results of Recent Exploration”, Brittonia 36 (2): 104-139.

Godelier, M. (1964) "Economie politique et anthropologie économique; à propos des Siane de Nouvelle-Guinée”, L'Homme (4) 3: 128-132.

Godelier, M. \& J. Garanger (1973) «Outils de pierre, outils d'acier chez les Baruya de Nouvelle-Guinée», L'Homme (13) 3: 128-139.

Lizot, J. (1977) «Population, ressources et guerre», Libre 77 (2): 115-145. (1980) «La agricultura yanomami», Antropológica 53: 3-93.

Morán, E. (1982) Human Adaptability: an Introduction to Ecological Anthropology. Boulder, Westview Press [1 ra ed.1979].

(1993) La Ecología humana de los pueblos de Amazonia. México: Fondo de Cultura Económica.

Roos, E. (1976) The Achuara Jivaro. Cultural Adaptation in the Upper Amazon. Ph. D. tesis, Columbia University. Ann Arbor (Michigan): Xeros University Microfilms.

Salisbury, R. (1962) From Stone to Steel. Cambridge: Cambridge University Press.

Sanchez, P. (1976) Properties and Managment of Soils in the Tropics. New York: John Wiley.

Sastre, C. (1975) «La végétation du haut et moyen Igara-Parana et les modifications apportées par les cultures sur brûlis», en J. Centlivres, J. Gashé \& A. Lourteigd, eds., Culture sur brûlis et évolution du milieu forestier en Amazonie du nord-ouest: 31-44. Genève: Société suisse d'ethnologie.

Schnell, R. (1972) Introduction à la phytogéographie des pays tropicaux. Paris: GauthierVillars, 2 tomes. 
Sioli, H. (1964) "General Features of the Limnology of Amazonia", Verhandlungen des International Verein Limnologie 15:1053-1058.

(1973) "Recent Human Activities in the Brazilian Amazon and their Ecological Effects", in B. Meggers, E. Ayensu \& W. Ducknorth, eds., Tropical Forest Ecosystems in Africa and South América: a Comparative Review: 321-334. Washington: Smithsonian Institution.

Smole, W., (1976) The Yanoama Indians: a Cultural Geography. Austin: University of Texas. (1989) "Yanoama Horticulture in the Parima Highlands of Venezuela and Brazil", in Darrel A. Posey \& William Baylée, eds., "Resource Managment in Amazonia: Indigenous and Folk Strategies", Advances in Economic Botany 7: 115-128. 